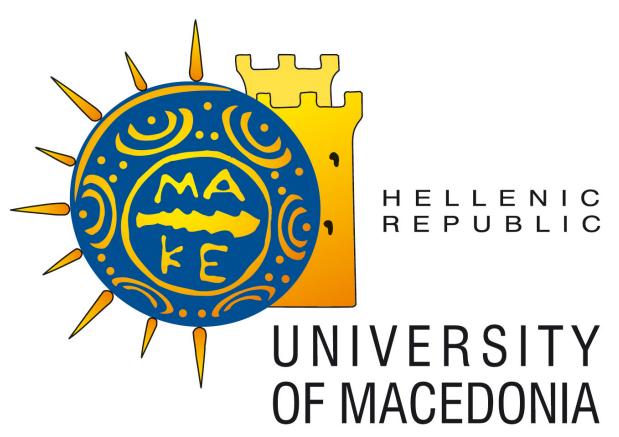

ISSN 1791-3144

\author{
University of Macedonia \\ Department of Economics
}

\author{
Discussion Paper Series
}

\title{
On the effect of Cournot and Stackelberg competition in the banking sector on the investment cycle
}

\author{
Eleni Dalla
}

\section{Discussion Paper No. 2/2017}

Department of Economics, University of Macedonia, 156 Egnatia str, 54006 Thessaloniki, Greece, Fax: + 30 (0) 2310891292

http://www.uom.gr/index.php?newlang=eng\&tmima=3\&categorymenu=2 


\title{
ON THE EFFECT OF COURNOT AND STACKELBERG COMPETITION IN THE BANKING SECTOR ON THE INVESTMENT CYCLE
}

\author{
Eleni Dalla ${ }^{1}$ \\ Department of Economics, University of Macedonia, Thessaloniki, Greece \\ E-mail: dalla@uom.edu.gr
}

\begin{abstract}
Following the industrial organization approach to banking, we investigate the effects of banking conduct on the investment cycle. To achieve this, we extend the second order accelerator (SOA) model in discrete time, introducing the interest rate on loans. To the extent that the banking sector is concerned, we consider two different types of banking conduct: a Cournot game where the banks make their decision on the quantities of loans and deposits simultaneously, and a Stackelberg game in which they decide over these amounts sequentially. In addition, we follow a simulation process to confirm the dynamic properties of our theoretical findings and examine the effects of monetary policy on capital over time.
\end{abstract}

Key Words: Cournot game, Stackelberg game, investment cycle, second order accelerator, monetary policy

JEL Codes: G21, L13, D92, E32, E52

\section{Acknowledgements}

The author would like to thank Erotokritos Varelas for his guidance and useful comments.

\footnotetext{
${ }^{1}$ Scholar of the Onassis Foundation
} 


\section{Introduction}

The existence of adjustment costs in the transformation of the investment expenditure into capital has been usually used in the investment literature to describe the discrepancy between actual and desired capital (Hay \& Morris, 1991). The second order accelerator mechanism (SOA) provides an explanation of the endogenous origination of the investment cycle, implying the presence of investment costs both in the changes of capital stock and in the changes of the level of investment. Also, it complies with the stylized facts (Hillinger \& Sebold Bender, 1992; A' Hearn \& Woitek, 2001) that imply a major role for investment in the business cycle. The inertia of investment, that is all the factors that cause the time lag in the transformation of investment expenditure into capital, underlies behind the second order accelerator mechanism. Hillinger et al. (1992) establish a second order accelerator model for fixed investment and inventories in continuous time, considering the intertemporal minimization problem of adjustment costs by the individual firm. In the same manner, Hillinger (2005) presents two further derivations of SOA: the standard flexible accelerator and the inference of the observed fluctuations into dynamic equations. Hillinger \& Weser (1988) and Weser (1992) study the aggregation problem in the business cycles theory in the SOA context. Along the same lines, Woitek (1995) and Barnett et al. (1996) examine the business cycle stylized facts empirically. Dalla \& Varelas (2016) derive a SOA model for fixed investment in discrete time, using the flexible accelerator. In the same context, Dalla et al. (2016) extend the previous model, introducing an exogenous interest rate on loans as an unknown function of time.

In this paper, we consider the implications of banking conduct on the investment cycle. For this reason, we extend the second order accelerator model in discrete time (Dalla \& Varelas, 2016), introducing the interest rate on loans which is supposed to be endogenous. Relating the firms' investment decision with the oligopolistic banking sector, we present two concepts of our model. In the first case, we consider a traditional Cournot game in which the banks make their decision on the quantities of loans and deposits simultaneously. In the second case, we assume a Stackelberg game in which they act strategically. Our purpose is the investigation of the effects of the banking conduct on the path of capital. The simulation process is put forward to verify our theoretical results and examine the effectiveness of monetary policy. 
The implication of the industrial organization theory on the behavior of the banking firm constitutes the so-called industrial organization approach to banking (Freixas \& Rochet, 2008; Van Hoose, 2010). The Monti-Klein (1971) model provides an analysis of the behavior of a monopolistic bank. Dalla \& Varelas (2013) analyze the effect of monetary policy on the interest rate spread in a monopolistic banking sector. Freixas \& Rochet (2008) establish a Cournot model with a finite number of banks and show that the optimal interest rates on loans and deposits increase after an increase in the interbank rate. Similarly, Toolsema \& Schoonbeek (1999) examine the effects of monetary policy via the interbank rate in the case of asymmetry in the cost function (Cournot game) and a Stackelberg game. Stahl (1988) and Yanelle (1989) consider a Bertrand game in the banking industry. Salop (1979) presents a model of monopolistic competition in the banking sector, assuming product differentiation because of the location and the transport costs. Using the aforementioned model and assuming a three stage game, Toolsema (2001) considers different types of monetary policy rules. Varelas (2007) examines the effects of monetary policy via the interbank rate on the bank-clients' behavior in a two-stage Cournot game with scope economies (Yamazaki \& Miyamoto, 2004). In the same context, Dalla et al. (2014) analyze the effect of a change in the minimum reserve requirements on both the banking and the consumers' behavior.

The rest of the paper is organized as follows. Section 2 summarizes the threeequation SOA model for fixed investment in discrete time (Dalla \& Varelas, 2015). Section 3 presents the endogenous monetary term augmented SOA model while section 4 provides the solution. In sections 5 and 6 , the calibration and the simulation processes are showed respectively. Section 7 examines the effects of monetary policy on the time path of capital. Section 8 concludes.

\section{The SOA Model in Discrete Time}

The second order accelerator mechanism (Hillinger et al., 1992; Hillinger, 2005) for fixed investment in discrete time (Dalla \& Varelas, 2016) is derived by the following three-equation structural model:

$$
\begin{array}{cl}
I_{t}-I_{t-1}=c\left(I_{t}^{*}-I_{t-1}\right), & 0<c<1 \\
I_{t}^{*}=b\left(K_{t}^{*}-K_{t-1}\right), \quad b>0
\end{array}
$$




$$
I_{t}=K_{t}-K_{t-1}
$$

where $c$ : the speed of adjustment, $b$ : a parameter of investors' behavior, $I_{t}^{*}:$ the desired level of fixed investment, $I_{t}$ : the actual level of fixed investment, $K_{t}$ : the actual level of capital and $K_{t}^{*}$ : the desired level of capital.

Equation (1) presents the partial adjustment mechanism for net investment. It shows that net investment is adjusted towards the desired level $\left(I_{t}^{*}\right)$ gradually. The coefficient $c \in(0,1)$ is the speed of adjustment. The closer to unity is the value of $c$, the faster is the adjustment of net investment in the present period. Conversely, as the value of $c$ approaches zero, the adjustment becomes slower. The validity of this mechanism is related to the existence of adjustment costs, implying that the presence of adjustment costs provokes the partial adjustment of net investment $\left(I_{t}\right)$ towards its desired level.

Relation (2) is a behavioral equation. It expresses the desired level of net investment $\left(I_{t}^{*}\right)$ as a positive function of the difference between the desired level of capital $\left(K_{t}^{*}\right)$ and the actual value of capital with a unity-period lag $\left(K_{t-1}\right)$. The introduction of the time pattern of the investment expenditure leads to a time lag in the transformation of this expenditure into capital. Under the assumption of a finite time path, the desired level of capital is assumed to be stable. This allows the notation of the desired level of capital with $K^{*}$ for the rest of the analysis. Finally, equation (3) is the definition of net investment.

Now, the combination of equations (1) to (3) yields the second order accelerator for fixed investment, which is expressed by the following second-order difference equation:

$$
K_{t}+[c(b+1)-2] K_{t-1}+(1-c) K_{t-2}=c b K^{*}
$$

The general solution of equation (4) is given by the sum of the general solution of the corresponding homogeneous difference equation and a particular solution of (4). To begin with the former, it shows the deviation of capital from its steady-state. The functional form of this general solution depends on the sign of the discriminant of the characteristic equation. Taking into consideration that, the homogeneous equation, as this is obtained by (4), has the following mathematical form: 


$$
K_{t}+[c(b+1)-2] K_{t-1}+(1-c) K_{t-2}=0
$$

the corresponding characteristic equation is:

$$
\lambda^{2}+[c(b+1)-2] \lambda+(1-c)=0
$$

and the crucial for this analysis value of the discriminant of the characteristic equation is:

$$
\Delta=c^{2}(b+1)^{2}-4 c b
$$

It is demonstrated that in the case of a negative discriminant, the homogeneous equation (5) generates trigonometric oscillations with period equal to $2 \pi / \omega$. The characteristic roots are conjugate complex numbers with modulus or absolute value ( $R$ ) equal to $R=\sqrt{1-c}$. From the assumptions of the structural model concerning the value interval of $c$, it is deduced that the absolute value of the complex conjugate roots is less than unity. Therefore, capital converges towards its equilibrium, following a trigonometric oscillatory path with decreasing amplitude. The stability of this system can also be ensured by the satisfaction of a set of necessary and sufficient conditions (Gandolfo, 1996). The critical condition for the existence of dynamic stability is inequality (8):

$$
c(b+2)<4
$$

Regarding the particular solution of (4), it can be interpreted as the equilibrium level of capital. Applying the method of undetermined coefficients, we obtain that:

$$
\overline{K_{t}}=K^{*}
$$

Hence, the steady-state of capital is equal to its desired level.

On the whole, the behavior of capital over time in the case of the trigonometric oscillatory movement is described by the following equation, which is also the general solution of this model:

$$
K_{t}=R^{t}\left[A_{1} \cos \omega t+A_{2} \sin \omega t\right]+K^{*}
$$

where $A_{1}, A_{2} \in \mathbb{R}$ are arbitrary constants which can be derived using two initial conditions.

\section{Extension of the Model: The Endogenous Monetary Term}

In this section, we propose an augmented second order accelerator model for fixed investment in discrete time that incorporates an endogenous monetary term, the interest rate on loans. In the context of an oligopolistic banking sector with two banks, 
1 and 2, that operate both on the markets for loans and deposits, we consider two different kinds of banking interaction. Under the assumption of finite time horizon, we begin with a traditional Cournot game where the banks compete over the volume of deposits and loans simultaneously. Then, we examine a Stackelberg game where the banks choose the volume of deposits and loans sequentially. It should be mentioned that in each period $t$ the individual bank acts in the context of the corresponding game, without reacting in the past actions of the rival bank. Thus, in each period $t$ the equilibrium interest rate on loans $\left(r_{L t}^{*}\right)$ is the solution of the corresponding static game. Our structural model has as follows:

$$
\begin{gathered}
I_{t}-I_{t-1}=c\left(I_{t}^{*}-I_{t-1}\right), \quad 0<c<1 \\
I_{t}^{*}=b\left(K_{t}^{*}-K_{t-1}\right)+d r_{L t}, \quad b>0, d<0 \\
I_{t}=K_{t}-K_{t-1} \\
Y_{t}=A K_{t}, \quad A>0 \\
L_{t}=L_{1 t}+L_{2 t} \\
D_{t}=D_{1 t}+D_{2 t} \\
r_{L t}=r_{L}\left(L_{t}, Y_{t}\right)=\mu_{1} Y_{t}-b_{1} L_{t}, \quad \mu_{1}, b_{1}>0 \quad \& r_{L}{ }^{\prime}\left(L_{t}\right)<0 \\
r_{D t}=r_{D}\left(D_{t}\right)=\beta_{1}+\gamma D_{t}, \quad \beta_{1}, \gamma>0 \& r_{D}{ }^{\prime}\left(D_{t}\right)>0 \\
\prod_{i t}=\prod_{i}\left(L_{i t}, D_{i t}\right)=r_{L}\left(L_{t}, Y_{t}\right) \cdot L_{i t}+r \cdot M_{i t}-r_{D}\left(D_{t}\right) \cdot D_{i t}-C_{i}\left(L_{i t}, D_{i t}\right) \quad i=1,2 \\
M_{i t}=(1-a) \cdot D_{i t}-L_{i t}, \quad i=1,2, \quad a \in(0,1) \\
C_{i t}=C_{i}\left(L_{i t}, D_{i t}\right)=\theta L_{i t}+\varphi D_{i t}, \quad \theta>0, \varphi>0, i=1,2
\end{gathered}
$$

Relations (11) (13) compose the second order accelerator model for fixed investment extended by the endogenous monetary term. As we can see, the difference from the initial model lies in the behavioral equation of investors, equation (12), where the interest rate on loans is introduced. The parameter $d$ is negative, expressing the negative relation between the interest rate on loans and the desired level of net 
investment. Moreover, under the assumption of the absence of substitution among the factors of production, the production function is given by equation (14), where $A>0$ denotes the parameter of technology.

Relations (15) to (21) determine the oligopolistic banking sector. In particular, equations (15) and (16) describe the total volumes of loans and deposits respectively, where $L_{i t}$ and $D_{i t}$ denote the individual amounts of loans and deposits of each bank. In addition, equation (17) is the inverse demand function for loans. Furthermore, the inverse supply function for deposits is given by equation (18). The interest rate on deposits $\left(r_{D t}\right)$ is a positive function of the total amount of deposits $\left(D_{t}\right)$. Equation (19) represents the profit function of the individual bank. The profit of the bank $i$ is obtained from the difference between its total revenues and total costs. In particular, total revenues derive from the interest rate on loans $\left(r_{L t}\right)$ and the exogenous interbank rate $(r)$ if the net position of the bank $\left(M_{i t}\right)$ is positive. On the other hand, total cost originates from the interest rate on deposits $\left(r_{D t}\right)$ paid to depositors and the cost function $\left(C_{i t}\right)$. Indeed, the exogenous interbank rate $(r)$ is also included in total costs if the net position of the bank $i\left(M_{i t}\right)$ is negative.

Equation (20) presents the net position of bank $i$ in the interbank market which is assumed to be linear. This function reflects the typical balance sheet constrain of the individual bank. The fraction of reserve requirements $(a \in(0,1))$ constitutes an exogenous instrument of monetary policy. Finally, the cost function of bank $i$ is given by equation (21) and is assumed linear as well. The parameters $\theta>0$ and $\varphi>0$ denote the marginal cost of loans and deposits respectively.

\section{Solution of the Model}

From equations (11) to (13), we obtain the reduced form in the product market in terms of capital:

$$
K_{t}+[c(b+1)-2] K_{t-1}+(1-c) K_{t-2}=c b K^{*}+c d r_{L t}
$$

Moving now into the oligopolistic banking sector, the maximization problem of the individual bank can be stated as:

$$
\max _{L_{i t}, D_{i t}} \Pi_{i}\left(L_{i t}, D_{i t}\right)=r_{L}\left(L_{t}, Y_{t}\right) \cdot L_{i t}+r \cdot M_{i t}-r_{D}\left(D_{t}\right) \cdot D_{i t}-C_{i}\left(L_{i t}, D_{i t}\right)
$$


In the context of the Cournot duopoly, each bank is profit maximizing given the volumes of deposits and loans of the other bank. Then, the interest rates on deposits and loans are determined in the corresponding market. Therefore, solving the above maximization problem and using the production function (14), we derive the equilibrium interest rate on loans as a function of capital:

$$
r_{L t}^{*}=\frac{A \mu_{1}}{3} K_{t}+\frac{2}{3}(r+\theta)
$$

On the other hand, in the case of the Stackelberg game the banks act strategically, deciding over the amounts of deposits and loans sequentially. More specifically, in the first stage, the "leader" bank (bank 1) chooses its own level of deposits and loans. In the second stage, the "follower" bank (bank 2) maximizes its profit function taking the leader bank's volumes of deposits and loans as given. The interest rates on deposits and loans are then determined in the corresponding market. So, following the backward induction method to solve this game and using the production function (14), we get the equilibrium interest rate on loans in terms of capital:

$$
r_{L t}^{*}=\frac{A \mu_{1}}{4} K_{t}+\frac{3}{4}(r+\theta)
$$

After the substitution of relations (24) \& (25) in (22), we derive the second order accelerator model for fixed investment in the respective case. Their functional forms are described by equations (26) \& (27) respectively:

$$
\begin{gathered}
{\left[1-\frac{A c d \mu_{1}}{3}\right] K_{t}+[c(b+1)-2] K_{t-1}+(1-c) K_{t-2}=c b K^{*}+\frac{2 c d}{3}(r+\theta)} \\
\& \\
{\left[1-\frac{A c d \mu_{1}}{4}\right] K_{t}+[c(b+1)-2] K_{t-1}+(1-c) K_{t-2}=c b K^{*}+\frac{3 c d}{4}(r+\theta)}
\end{gathered}
$$

Both relations (26) \& (27) are second order difference equations with constant coefficients. Following the same methodology with the initial model, firstly we determine the general solution of the homogeneous equations corresponding to equation (26) and (27), that is of:

$$
\left[1-\frac{A c d \mu_{1}}{3}\right] K_{t}+[c(b+1)-2] K_{t-1}+(1-c) K_{t-2}=0
$$




$$
\left[1-\frac{A c d \mu_{1}}{4}\right] K_{t}+[c(b+1)-2] K_{t-1}+(1-c) K_{t-2}=0
$$

The relative characteristic equations are respectively:

$$
\begin{gathered}
{\left[1-\frac{A c d \mu_{1}}{3}\right] \lambda^{2}+[c(b+1)-2] \lambda+(1-c)=0} \\
\& \\
{\left[1-\frac{A c d \mu_{1}}{4}\right] \lambda^{2}+[c(b+1)-2] \lambda+(1-c) K_{t-2}=0}
\end{gathered}
$$

The discriminant in each case has as follows:

$$
\begin{gathered}
\Delta_{1}=[c(b+1)-2]^{2}-4\left[1-\frac{A c d \mu_{1}}{3}\right](1-c) \\
\& \\
\Delta_{2}=[c(b+1)-2]^{2}-4\left[1-\frac{A c d \mu_{1}}{4}\right](1-c)
\end{gathered}
$$

In both cases of banking interaction, the second order accelerator mechanism can interpret the existence of the investment cycles if the value of the corresponding discriminant is negative. Therefore, under the assumption of the negative discriminant in the Cournot game, capital follows a trigonometric oscillatory path with period equal to $2 \pi / \omega_{1}$. The characteristic roots are conjugate complex numbers with modulus or absolute value equal to $R_{1}=\sqrt{[3(1-c)] /\left(3-A c d \mu_{1}\right)}>0$. If the latter's value is less than unity, the amplitude of the trigonometric oscillations is decreasing leading to the capital's convergence towards the equilibrium. The set of necessary and sufficient conditions for convergence to exist has as follows:

$$
\begin{gathered}
\frac{c\left(3 b-A d \mu_{1}\right)}{3-A c d \mu_{1}}>0, \quad 3-A c d \mu_{1} \neq 0 \\
\frac{c\left(3-A d \mu_{1}\right)}{3-A c d \mu_{1}}>0, \quad 3-A c d \mu_{1} \neq 0 \\
\frac{3[4-c(b+2)]-A c d \mu_{1}}{3-A c d \mu_{1}}>0, \quad 3-A c d \mu_{1} \neq 0
\end{gathered}
$$

Given the assumption of the negative discriminant, in the Stackelberg game the resulting movement of capital is similar, i.e. a trigonometric oscillatory path with period equal to $2 \pi / \omega_{2}$ and a decreasing amplitude if and only if the modulus or 
absolute value of the corresponding characteristic roots is less than unity. The latter is calculated equal to $R_{2}=\sqrt{[4(1-c)] /\left(4-A c d \mu_{1}\right)}>0$. In this case, the necessary and sufficient conditions are given by the following inequalities:

$$
\begin{gathered}
\frac{c\left(4 b-A d \mu_{1}\right)}{4-A c d \mu_{1}}>0, \quad 4-A c d \mu_{1} \neq 0 \\
\frac{c\left(4-A d \mu_{1}\right)}{4-A c d \mu_{1}}>0, \quad 4-A c d \mu_{1} \neq 0 \\
\frac{4[4-c(b+2)]-A c d \mu_{1}}{4-A c d \mu_{1}}>0, \quad 4-A c d \mu_{1} \neq 0
\end{gathered}
$$

Now, we apply the method of undetermined coefficients to obtain the particular solutions of equations (26) and (27). These solutions are interpreted as the equilibrium level of capital in each case of banking interaction. For this reason, they should be positive. Their functional form has as follows ${ }^{2}$ :

$$
\begin{gathered}
\overline{K_{t}}=\frac{2 d(r+\theta)+3 b K^{*}}{3 b-A d \mu_{1}}, 3 b-A d \mu_{1} \neq 0 \\
\& \\
\overline{K_{t}}=\frac{3 d(r+\theta)+4 b K^{*}}{4 b-A d \mu_{1}}, 4 b-A d \mu_{1} \neq 0
\end{gathered}
$$

At this point we have to mention that we expect a lower equilibrium level of capital in the case of the Cournot game (relation (36)) rather than in the case of the Stackelberg game (relation (37)). This remark is a result of the intuition behind the comparison between the Cournot and the Stackelberg equilibria (Church \& Ware, 2000). In particular, the total equilibrium Cournot level of loans is lower than the Stackelberg one. Consequently, the inverse demand function for loans implies that the equilibrium interest rate on loans is higher in the case of the Cournot interaction. Taking into consideration that net investment is related inversely to the interest rate on loans, the steady-state of capital should be lower in the Cournot model rather than in Stackelberg model.

To conclude, the behavior of capital over time in the cases of the Cournot and the Stackelberg game is described by the following equations respectively:

\footnotetext{
${ }^{2}$ The restrictions $3 b-A d \mu_{1} \neq 0 \& 4 b-A d \mu_{1} \neq 0$ are satisfied in the case of convergence of capital towards its equilibrium due to the satisfaction of the corresponding set of stability conditions (34) \& (35).
} 


$$
K_{t}=R_{1}^{t}\left[A_{3} \cos \omega_{1} t+A_{4} \sin \omega_{1} t\right]+\frac{2 d(r+\theta)+3 b K^{*}}{3 b-A d \mu_{1}}, 3 b-A d \mu_{1} \neq 0
$$

$\&$

$$
K_{t}=R_{2}^{t}\left[A_{5} \cos \omega_{2} t+A_{6} \sin \omega_{2} t\right]+\frac{3 d(r+\theta)+4 b K^{*}}{4 b-A d \mu_{1}}, 4 b-A d \mu_{1} \neq 0
$$

where $A_{3}, A_{4}, A_{5}, A_{6} \in \mathbb{R}$ are arbitrary constants which can be derived using two initial conditions.

\section{Calibration}

We begin our analysis with the presentation of the values assigned to our model parameters. We follow the method of Karpetis \& Varelas (2012), assigning random values to the parameters and taking into consideration their value intervals in the theoretical model. To begin with the speed of adjustment $(c)$, its value interval is the $(0,1)$. We choose the value 0.4 that corresponds to a slow adjustment of net investment towards its desired level. In addition, the behavioral parameter $b$ is set equal to 1 . Given the desired level of capital, $b=1$ means that an increase in the present period's capital leads to a proportional decrease in the desired level of net investment with one period lead ceteris paribus. Reflecting the negative relation between the interest rate on loans and the desired level of net investment, $d$ is set equal to $-0.3<0$. Moreover, the parameter of technology $A$ is set equal to 2 while the desired level of capital $\left(K^{*}\right)$ is assumed equal to 15 .

Concerning the microeconomic parameters, we begin with the inverse demand function for loans. We set $\mu_{1}$ equal to $1.5>0$ to show that a marginal increase in national income results in an increase of the interest rate on loans by 1.5 units. Moreover, we assign the value 0.5 to the parameter $b_{1}$, so the slope of the demand function for loans is equal to -0.5 . The parameters of the inverse supply function for deposits, $\beta_{1} \& \gamma$, are determined to 30 and 1.2 respectively. Furthermore, the marginal costs of deposits $(\varphi)$ and loans $(\theta)$ are assigned to 1.5 and 2. Turning now to the policy parameters, both the fraction of minimum reserve requirements $(\alpha)$ and the interbank rate $(r)$ are equal to 0.1 . The following table summarizes our calibration: 


\begin{tabular}{|c|c|c|c|c|c|c|}
\hline \multicolumn{6}{|c|}{ Macroeconomic Parameters \& Parameters of Policy } \\
\hline $\boldsymbol{c}$ & $\boldsymbol{b}$ & $\boldsymbol{d}$ & $\boldsymbol{A}$ & $K^{*}$ & $\boldsymbol{\alpha}$ & $\boldsymbol{r}$ \\
\hline 0.4 & 1 & -0.3 & 2 & 15 & 0.1 & 0.1 \\
\hline \multicolumn{7}{|c|}{ Microeconomic Parameters } \\
\hline$\mu_{1}$ & $\boldsymbol{b}_{1}$ & $\beta_{1}$ & $\gamma$ & $\boldsymbol{\varphi}$ & $\boldsymbol{\theta}$ & \\
\hline 1.5 & 0.5 & 30 & 1.2 & 1.5 & 2 & \\
\hline
\end{tabular}

Table 1: Calibration

\section{Simulations ${ }^{3}$}

In the present section, we attempt to confirm the dynamic properties of our analysis and compare the initial SOA with the banking behavior augmented SOA given the calibration discussed before. Firstly, we calculate the discriminant of the characteristic equation in each case. Substituting the numerical values of the parameters in equations (7), (32) and (33) respectively, we find that the corresponding discriminants are negative. Therefore, capital follows a trigonometric oscillatory path in the context of the initial SOA model, as well as, under the Cournot and Stackelberg interaction. In addition, the absolute value of the conjugate complex roots in each concept of SOA model (that is $R=0.774597, R_{1}=0.731925 \& R_{2}=0.741929$ respectively) is less than unity, implying the stability of the corresponding equilibrium. As a result the relative stability conditions, i.e. (8), (34) and (35), are satisfied.

Regarding the phase of the investment cycle, in the standard SOA we find that $\sin \omega t=0.632455 \& \cos \omega t=0.774596$. Similarly, in the cases of the Cournot and the Stackelberg interaction, we have $\sin \omega_{1} t=0.681385 \& \cos \omega_{1} t=0.731925$ and $\sin \omega_{2} t=0.670478 \& \cos \omega_{2} t=0.741929$. From the trigonometric tables we accept that all the aforementioned values approximate the trigonometric values of the $2 \pi / 9$ radians angle. Therefore, we infer approximately that the resulting movement of capital in all the examined cases is a periodic oscillation with period equal to 9 and decreasing amplitude.

From equations (9), (36) and (37), the equilibrium level of capital in the cases of the initial SOA model, the Cournot competition and the Stackelberg game is deduced

\footnotetext{
${ }^{3}$ The simulation results of this section were derived using the program Wolfram Mathematica 9.0.
} 
equal to $15,11.2154$ and 11.8592 respectively. It is obvious that the introduction of the monetary term in the SOA model for fixed investment leads to a lower steadystate of capital. This is a matter of the negative relation between the investments and the interest rate on loans. What's more, as it was expected, the steady-state of capital is lower in the case of the Cournot model rather than in the Stackelberg one.

Assuming the initial conditions $K_{0}=8 \& K_{1}=20$ and using relations (10), (38) \& (39), we obtain the general solution of each concept of the SOA model:

$$
\begin{gathered}
K_{t}=(0.774597)^{t}\left[(-7) \cos \frac{2 \pi}{9} t+18.3844 \sin \frac{2 \pi}{9} t\right]+15 \\
K_{t}=(0.731925)^{t}\left[(-3.2154) \cos \frac{2 \pi}{9} t+22.5038 \sin \frac{2 \pi}{9} t\right]+11.2154 \\
\& \\
K_{t}=(0.741929)^{t}\left[(-3.8592) \cos \frac{2 \pi}{9} t+21.6694 \sin \frac{2 \pi}{9} t\right]+11.8592
\end{gathered}
$$

Equation (40) (42) describe the motion of capital in the cases of the initial SOA, the Cournot competition and the Stackelberg game respectively. Figure 1 depicts the paths of capital over time, as well as the steady-states in each case.

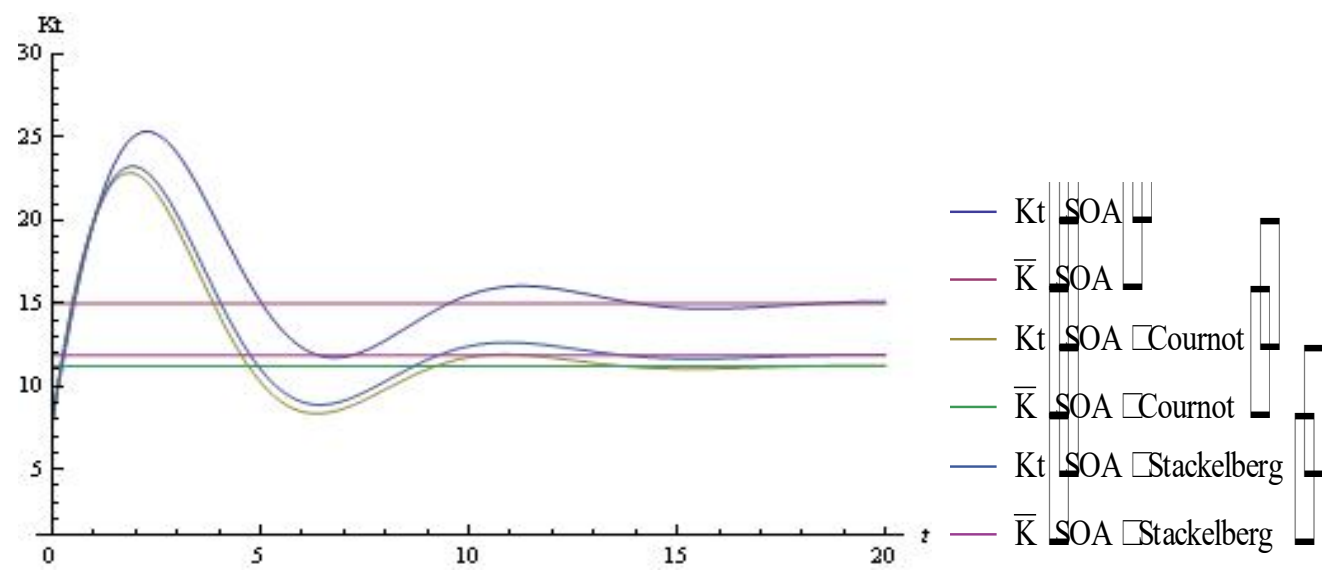

Figure 1: The motion of capital over time 


\section{Monetary Policy Implications ${ }^{4}$}

In the monetary term augmented SOA model both the minimum reserve requirements and the interbank rate are determined exogenously by the Central Bank. Relations (24) and (25) imply that the interest rate on loans, both under the assumption of the Cournot interaction, as well as, when the Stackelberg interaction is the case, depends on the interbank rate. Therefore, monetary policy via the interbank rate affects the equilibrium interest rate on loans and consequently the path of capital over time. Taking into consideration that our model is deterministic which implies full information, perfect foresight and no uncertainty, we examine the effects of expansionary monetary policy via the interbank rate on the motion of capital.

We assume that capital lies on the steady-state at the period $t=0$ either when the Cournot interaction is the case or when the Stackelberg game is considered. At period $t=1$, the Central bank implements expansionary monetary policy, decreasing the interbank rate from 0.1 to 0.05 . Figures 2 and 3 show the resulting transition path of capital for the Cournot and Stackelberg game respectively. It can be clearly seen that in both cases the decrease in the interbank rate leads to an increase in capital from its initial steady-state to a new higher steady-state over 19 periods. Hence, monetary policy via the interbank rate is effective.

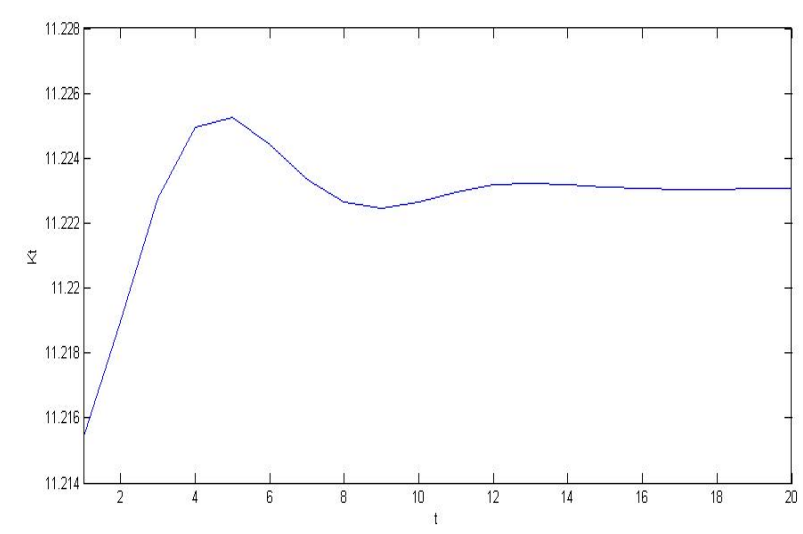

Figure 2: Expansionary monetary policy Cournot game

${ }^{4}$ The results of monetary policy were deduced using the Matlab R2008a software. 


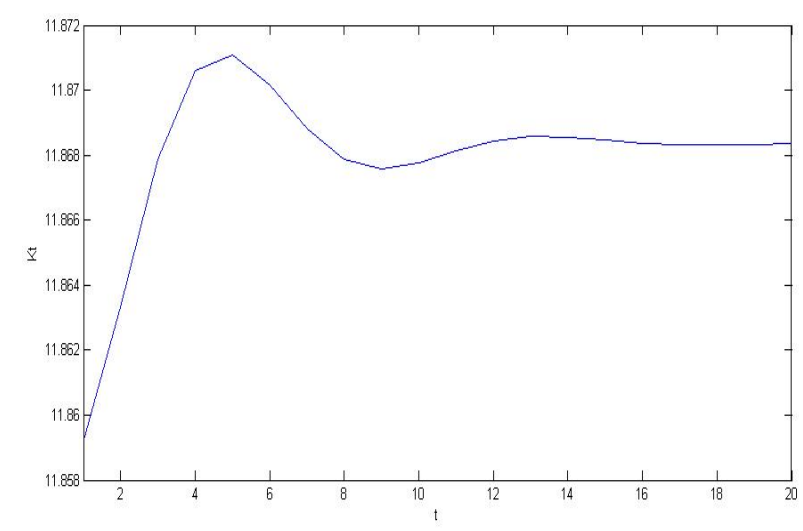

Figure 3: Expansionary monetary policy Stackelberg game

\section{Conclusion}

In this paper, we extended the second order accelerator model for fixed investment in discrete time (Dalla \& Varelas, 2016), incorporating the endogenous interest rate on loans in it. Following the industrial organization approach to banking and considering, on the one hand, a Cournot game of banking interaction and on the other a Stackelberg game, we investigated the effects of the introduction of this endogenous monetary term on the ability of the SOA mechanism to originate investment cycles. We found that our augmented model can interpret the existence of investment cycles in terms of capital as well.

Moreover, we proceeded to a simulation process. Our results verified the dynamic properties of our theoretical system. The comparison between the standard threeequation SOA model and the two versions of the endogenous monetary term augmented SOA model showed that in all the cases capital follows a trigonometric oscillatory path that converges towards the steady-state. The difference among the three concepts of SOA lies on the equilibrium level of capital. As it was expected, the introduction of the interest rate on loans leads to a lower steady-state of capital, with the latter being even lower in the case of Cournot interaction in the banking sector. Finally, we examined the implications of monetary policy on the path of capital over time. It was demonstrated that monetary policy via the interbank rate is effective in the case of the Cournot game as well as in the case of the Stackelberg one. 


\section{References}

1. A' Hearn, Brian and Ulrich Woitek (2001), More International Evidence on the Historical Properties of Business Cycles, Journal of Monetary Economics, 47, 321-346.

2. Barnett, William, Giancarlo Gandolfo and Claude Hillinger (1996), Dynamic Disequilibrium Modeling, New York: Cambridge University Press.

3. Church, Jeffry and Roger Ware (2000), Industrial Organization: A Strategic Approach, McGraw-Hill. Publishing Co.: International Editions, Management \& Organization Series.

4. Dalla, Eleni, Christos Karpetis and Erotokritos Varelas (2014), Monetary Policy Implications on Banking Conduct and Bank-Clients' Behavior, Atlantic Economic Journal, 42.

5. Dalla, Eleni, Christos Karpetis and Erotokritos Varelas (2016), Modeling Investment Cycle: A Theoretical Analysis, Modern, 7, 336-344.

6. Dalla, Eleni and Erotokritos Varelas (2013), Monetary Policy and the Behavior of a Monopolistic Bank: A Theoretical Approach, Asian Economic and Financial Review, 3, 11, 1439-1450.

7. Dalla, Eleni and Erotokritos Varelas (2016), Second-Order Accelerator of Investment: The Case of Discrete Time, International Review of Economics Education, 21, 48-60.

8. Freixas, Xavier and Jean-Charles Rochet (2008), Microeconomics of Banking, Second Edition, Cambridge: The MIT Press.

9. Gandolfo, Giancarlo (1996), Economic Dynamics, Third Edition, Berlin Heidelberg: Springer-Verlag.

10. Hay, Donald and Derek Morris (1991), Industrial Economics and Organization: Theory and Evidence, Second Edition, New York: Oxford University Press.

11. Hillinger, Claude (2005), Evidence and Ideology in Macroeconomics: The Case of Investment Cycles, Munich Discussion Paper No. 2005-16.

12. Hillinger, Claude, Michael Reiter and Thilo Weser (1992), Micro Foundations of the Second-Order Accelerator and of Cyclical Behavior, In Claude Hillinger (eds.), Cyclical Growth in Market and Planned Economies, Oxford: Oxford University Press.

13. Hillinger, Claude and Monika Sebold-Bender (1992), The Stylized Facts of Macroeconomic Fluctuations, In Claude Hillinger (eds.), Cyclical Growth in Market and Planned Economies, Oxford: Oxford University Press.

14. Hillinger, Claude and Thilo Weser (1988), The Aggregation Problem in Business Cycle Theory, Journal of Economic Dynamics and Control, 12, 37-40.

15. Karpetis, Christos and Erotokritos Varelas (2012), Fiscal and Monetary Interaction in a Simple Accelerator Model, International Advances in Economic Research, 18, 199-214.

16. Klein, Michael (1971), A Theory of the Banking Firm, Journal of Money, Credit and Banking, 3, 205-218.

17. Monti, M. (1972). Deposit, Credit, and Interest Rate Determination under Alternative Bank Objectives. In: Mathematical Methods in Investment and Finance, (eds.) G. P. Szego and K. Shell. Amsterdam: North-Holland.

18. Salop, Steven (1979), Monopolistic Competition with Outside Goods, The Bell Journal of Economics, 141-156.

19. Stahl, Dale. O. (1988), Bertrand competition for inputs and Walrasian outcomes, The American Economic Review, 189-201. 
20. Toolsema-Veldman, Linda. (2001), Bank competition with product differentiation under different monetary policy rules, Groningen: University of Groningen, SOM research school, http://www.rug.nl/research/portal/publications/bank-competitionwith-product-differentiation-under-different-monetary-policy-rules(aa159c6a2420-457d-a5d3-95c108845abb)/export.html

21. Toolsema-Veldman, Linda and Lambert Schoonbeek(1999), Bank Behavior and the Interbank Rate in an Oligopolistic Market, SOM Research Reports, University of Groningen, http://irs.ub.rug.nl/ppn/190864370.

22. Van Hoose, David (2010), The Industrial Organization of Banking: Bank Behavior, Market Structure, and Regulation. Berlin, Heidelberg: Springer-Verlag.

23. Varelas, Erotokritos (2007), Methodological Study of Welfare of the Bank-Clients in the Yamazaki and Miyamoto Model, Journal of Financial Management and Analysis, 20, 69-75.

24. Weser, Thilo (1992), The Aggregation Problem for Economic Cycles, In Claude Hillinger (eds.), Cyclical Growth in Market and Planned Economies, Oxford: Oxford University Press.

25. Woitek, Ulrich (1995), Business Cycles: An International Comparison of Stylized Facts in a Historical Perspective, Heidelberg: Physica-Verlag.

26. Yamazaki, Shota and Hiroaki Miyamoto (2004), A Note on Bank Behavior and Monetary Policies in an Oligopolistic Market, RePec, EconWPA - Industrial Organization, No 0408003. http://128.118.162/eps/io/papers/0408003.pdf

27. Yanelle, Marrie - Odile (1989), The Strategic Analysis of Intermediation, European Economic Review, 33, 294-301. 